\title{
Identification of Weakly Beta-Hemolytic Porcine Spirochetes by Biochemical Reactions, PCR-Based Restriction Fragment Length Polymorphism Analysis and Species-Specific PCR
}

\author{
Tatsuo OHYA ${ }^{1) *}$, Hiroshi ARAKI ${ }^{2)}$ and Masuo SUEYOSHI ${ }^{3)}$ \\ ${ }^{1)}$ Kyushu Research Station, Environmental/Enzootic Diseases Research Team, National Institute of Animal Health, 2702 Chuzan, \\ Kagoshima 891-0105, ${ }^{2)}$ Nagasaki Prefecture Kenhoku Livestock Hygiene Service Center, 92 Takebe, Sasebo 858-091 and ${ }^{3)}$ Department \\ of Veterinary Hygiene, Faculty of Agriculture, Miyazaki University, Miyazaki 889-2155, Japan
}

(Received 27 November 2007/Accepted 21 April 2008)

ABSTRACT. We examined the usefulness of PCR-based restriction fragment length polymorphism (PCR-RFLP) and species-specific PCR combined with a newly devised rapid biochemical test using microplates for identifying weakly beta-hemolytic intestinal spirochetes (WBHIS) isolated from pigs. WBHIS strains showing atypical biochemical characteristics were decisively identified at the species level by PCR-RFLP and species-specific PCR. Identification of WBHIS at the species level in routine diagnostic work will certainly contribute to clarifying the pathogenicity of WBHIS.

KEY WORDS: Brachyspira, PCR-RFLP, spirochete.

J. Vet. Med. Sci. 70(8): 837-840, 2008

Intestinal infections with Brachyspira species are responsible for severe economic losses in the swine industry worldwide. Brachyspira species identified in pigs include one strongly hemolytic species Brachyspira hyodysenteriae and 4 weakly beta-hemolytic intestinal spirochetes (WBHIS): B. innocens, B. pilosicoli, B. intermedia, and B. murdochii. B. hyodysenteriae is considered the most pathogenic species and causes swine dysentery $[6,17]$. B. pilosicoli has been linked to a milder colitis known as porcine intestinal (or colonic) spirochetosis $[5,14,15]$. These 4 species of weakly beta-hemolytic intestinal spirochete have a similar appearance on blood agar, and the pathogenicity of these species except $B$. pilosicoli is controversial. Although Kinyon and Harris [8] and Lee et al. [9] considered these species as non-pathogenic, other studies $[2,10]$ have provided evidence that even these species may induce enterocolitis.

Our bacteriological surveys of swine suffering from swine dysentery, colitis, or diarrhea, indicated that 49 strains of WBHIS were isolated in 21 cases and $B$. hyodysenteriae was isolated in 101 cases. Among the 21 cases, $B$. hyodysenteriae was isolated with WBHIS in three cases, and $B$. pilosicoli and B. innocens were isolated in one case. In the remaining 17 cases, only a single species of WBHIS was isolated.

Bacteriological examination of swine dysentery and related diseases is mainly focused on B. hyodysenteriae or B. pilosicoli. Moreover, precise identification of WBHIS tends to be neglected, and this may correlate to the insufficient description of their pathogenicity.

The aim of this study was to evaluate the usefulness of

\footnotetext{
* Correspondence to: Ohya, T., Kyushu Research Station, National Institute of Animal Health, 2702 Chuzan, Kagoshima 891-0105, Japan. e-mail: ohyat@affrc.go.jp
}

PCR-based restriction fragment length polymorphism (PCR-RFLP) and species-specific PCR combined with biochemical tests for identifying WBHIS.

Forty nine isolates of WBHIS were investigated in this study, and 4 additional type strains of Brachyspira species were included as references (Table 1).

Currently, porcine Brachyspira isolates are differentiated based on phenotypic criteria, including intensity of hemolysis, indole production, hippurate hydrolysis, and the activities of $\alpha$-galactosidase, $\alpha$-glucosidase, and $\beta$-glucosidase $[3,12]$.

The spirochetes were streaked on trypticase soy agar (TSA; Becton Dickinson Microbiology Systems, Sparks, MD., U.S.A.) containing 5\% sheep blood and incubated for three days under anaerobic conditions. Beta-hemolysis was classified as weak or strong, using the type strains of $B$. hyodysenteriae ATCC 27164 and B. innocens ATCC 29796 as references.

A rapid method for identifying weakly beta-hemolytic spirochetes based on biochemical characteristics was newly devised using 96-well round-bottomed microplates. The microplates were incubated aerobically for $2 \mathrm{hr}$ at $37^{\circ} \mathrm{C}$ prior to the addition of detection reagents.

Fresh growth of spirochetes on TSA with 5\% sheep blood was collected in phosphate buffered saline ( $\mathrm{pH} 7.2)$, and a bacterial suspension with an optical density similar to the McFarland number 8 standard was prepared. This dense suspension was used in $50 \mu l$ portions as inoculums for the following biochemical reactions.

Indole production was tested using tryptophan broth (0.5\% tryptophan, $0.2 \%$ dipotassium phosphate, $\mathrm{pH} 7.8$ ). Tryptophan broth $(50 \mu l)$ was mixed with an equal volume of bacterial suspension and incubated aerobically for $2 \mathrm{hr}$ at $37^{\circ} \mathrm{C}$, and $25 \mu l$ of Kovac's reagent was then added. Production of indole was confirmed by the formation of a pink 
Table 1. Identification of 49 field isolates of weakly beta-hemolytic porcine intestinal spirochetes by biochemical reactions, PCR-RFLP analysis, and species-specific PCR

\begin{tabular}{|c|c|c|c|c|c|c|}
\hline Strain & $\begin{array}{l}\text { Indole } \\
\text { production }\end{array}$ & $\begin{array}{l}\text { Hippurate } \\
\text { hydrolysis }\end{array}$ & $\begin{array}{l}\alpha \text {-galactosidase } \\
\text { activity }\end{array}$ & $\begin{array}{l}\beta \text {-glucosidase } \\
\text { activity }\end{array}$ & $\begin{array}{l}\text { Biochemical } \\
\text { group }\end{array}$ & $\begin{array}{l}\text { Species indicated by PCR-RFLP } \\
\text { and species-specific PCR }\end{array}$ \\
\hline NGS134/1997 & - & - & - & - & Not defined & B. pilosicoli \\
\hline AMR206/2006 & - & + & - & + & Atypical IV & B. pilosicoli \\
\hline NGS117/1997 & - & - & - & + & IIIa & B. innocens \\
\hline NGS118/1997 & - & - & - & + & IIIa & B. innocens \\
\hline NGS119/1997 & - & - & - & + & IIIa & B. innocens \\
\hline NGS120/1997 & - & - & - & + & IIIa & B. innocens \\
\hline AMR163/2004 & - & - & + & - & Not defined & B. innocens \\
\hline AMR164/2004 & - & - & + & - & Not defined & B. innocens \\
\hline STM44/1996 & - & - & - & + & IIIa & B. intermedia \\
\hline AMR207/2006 & + & - & - & + & II & B. intermedia \\
\hline KGS159/2000 & - & - & - & + & IIIa & B. murdochii \\
\hline KGS160/2000 & - & - & - & + & IIIa & B. murdochii \\
\hline KGS161/2000 & - & - & - & + & IIIa & B. murdochii \\
\hline KGS162/2000 & - & - & - & + & IIIa & B. murdochii \\
\hline AMR165/2004 & - & - & - & - & Not defined & B. murdochii \\
\hline AMR205/2006 & - & - & - & - & Not defined & B. murdochii \\
\hline Remaining & - & - & + & + & IIIbc & B. innocens \\
\hline 33 strains & & & & & & \\
\hline ATCC 51139 & - & + & + & - & IV & B. pilosicoli \\
\hline ATCC 29796 & - & - & + & + & IIIbc & B. innocens \\
\hline ATCC 51140 & + & - & - & + & II & B. intermedia \\
\hline ATCC 51284 & - & - & - & + & IIIa & B. murdochii \\
\hline
\end{tabular}

a) According to Fellström et al. [4].

to red color in alcohol layer around well within $10 \mathrm{~min}$. In addition, the spot indole test [1, 13] was performed by smearing the bacterial growth from a plate culture on a filter paper saturated with the indole reagent (1\% p-dimethylaminocinnamaldehyde in $10 \%$ hydrochloric acid). Positive reactions were indicated by a blue color development within 3 min. Negative reactions remained pink.

For hippurate hydrolysis test, $50 \mu l$ of $1 \%$ sodium hippurate in water was mixed with an equal volume of the dense suspension of each spirochete and incubated aerobically for $2 \mathrm{hr}$ at $37^{\circ} \mathrm{C}$. Two types of ninhydrin reagents (I and II) were prepared to compare the ability to detect the presence of glycine in the hippurate hydrolysis reaction mixture. Reagent I was composed of $3.5 \mathrm{~g}$ of ninhydrin in $100 \mathrm{~m} l$ of a 1:1 mixture of acetone and butanol [7]. The composition of reagent II was $7 \%$ ninhydrin in 2-methoxyethanol; this was adopted in the API identification system (bioMérieux SA, Marcy-l'Etoile, France). After incubation, $25 \mu l$ of each ninhydrin reagent was added and incubated for $10 \mathrm{~min}$. The reaction was judged to be positive if a deep blue or purple color developed and negative if the solution turned light blue or remained colorless. The examination of cellular $\alpha$ galactosidase and $\beta$-glucosidase activity was performed using commercial reagents. A $0.5 \%$ solution of 4-nitrophenyl $\alpha$-D-galactopyranoside (Sigma N0877) and 4-nitrophenyl $\beta$-D-glucopyranoside (Sigma N7006) in phosphate buffered saline (PBS, $\mathrm{pH}$ 7.2) was used as the substrate. Reactions were performed in the manner described above. Enzymatic activity was determined to be positive by the development of yellow color due to the release of a 4-nitro- phenyl residue from each substrate.

PCR-RFLP analysis for the Brachyspira NADH oxidase (nox) gene was performed by the method of Rhode et al. [11]. In brief, nox gene-specific PCR was performed for weakly beta-hemolytic and reference strains. An aliquot of the PCR product was digested with $\mathrm{Dpn}$ II and $\mathrm{Bfm}$ I, and the restriction fragments were separated in a $3 \%$ agarose gel and visualized after staining with ethidium bromide.

Additional species-specific PCR described by Weissenböck et al. [16] was used for decisive identification of porcine Brachyspira species. Species-specific PCR was performed under 4 different annealing temperatures ranging from 52 to $62^{\circ} \mathrm{C}$ for each species, and the PCR products were separated in the manner described above.

Thirty-three out of 49 WBHIS strains showed the characteristics of the biochemical group IIIbc described by Fellström et al. [4], which comprises B. innocens, and PCRRFLP analysis supported this identification (data not shown). Sixteen other strains had atypical or inconsistent biochemical characteristics but were identified at the species level by PCR-RFLP analysis (Fig. 1). Results of the decisive species-specific PCR are shown in Fig. 2.

Two field strains identified as B. pilosicoli showed atypical biochemical reactions. Strain NGS134/1997 was negative for hippurate hydrolysis, which is a distinct characteristic of B. pilosicoli. Strains AMR206/2006 and ATCC 51139 were positive for hippurate hydrolysis; however, positive reaction was detected only when ninhydrin reagent II was used. It was proved that ninhydrin reagent II is essential for accurate judgment for identifying Brachys- 


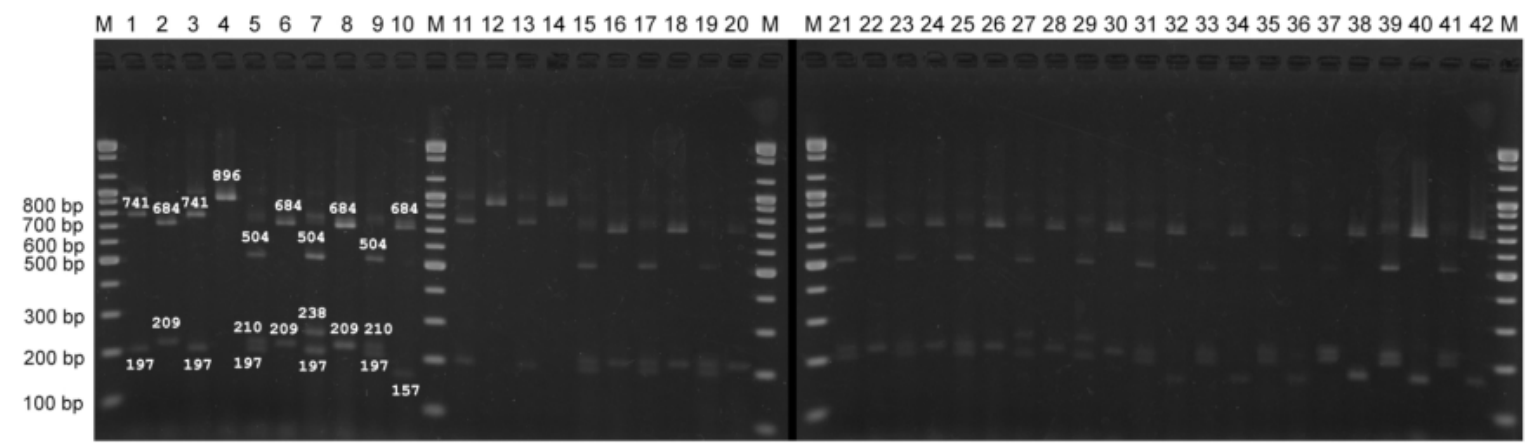

Fig. 1. RFLP analysis of the Brachyspira reference strains and 16 field isolates. Lane M: 100 bp DNA ladder; lanes 1, 2: B. hyodysenteriae ATCC 27164; lanes 3, 4: B. pilosicoli ATCC 51139; lanes 5, 6: B. innocens ATCC 29796; lanes 7, 8: B. intermedia ATCC 51140; lanes 9, 10: B. murdochii ATCC 51284; lanes 11, 12: NGS134/1997; lanes 13, 14: AMR206/2006; lanes 15, 16 : NGS117/1997; lanes 17, 18: NGS118/1997; lanes 19, 20: NGS119/1997; lanes 21,22: NGS120/1997; lanes 23, 24: AMR163/ 2004; lanes 25, 26: AMR164/2004; lanes 27, 28: STM44/1996; lanes 29, 30: AMR207/2006; lanes 31, 32: KGS159/2000; lanes 33, 34: KGS160/2006; lanes 35, 36: KGS161/2006; lanes 37, 38: KGS162/2000; lanes 39, 40: AMR165/2004; lanes 41, 42: AMR205/2006. Digestion was performed using Bfm I (odd-numbered lanes) and Dpn II (even numbered lanes). The small white numbers in lanes 1 to 10 are fragment sizes in base pairs.

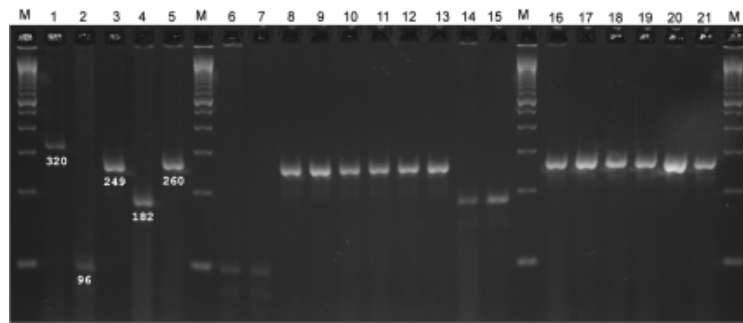

Fig. 2. Identification of Brachyspira species by species-specific PCR. Lane M: 100 bp DNA ladder; lane 1: B. hyodysenteriae ATCC 27164; lane 2: B. pilosicoli ATCC 51139; lane 3: B. innocens ATCC 29796; lane 4: B. intermedia ATCC 51140; lane 5: B. murdochii ATCC 51284; lane 6: NGS134/1997; lane 7: AMR206/2006; lane 8: NGS117/ 1997; lane 9: NGS118/1997; lane 10: NGS119/1997; lane 11: NGS120/1997; lane 12: AMR163/2004; lane 13: AMR164/2004; lane 14: STM44/1996; lane 15: AMR207/ 2006; lane 16: KGS159/2000; lane 17: KGS160/2006; lane 18: KGS161/2006; lane 19: KGS162/2000; lane 20: AMR165/2004; lane 21: AMR205/2006. The small white numbers in lanes 1 to 5 are fragment sizes in base pairs.

pira species. Two field isolates were finally identified as $B$. intermedia, and strain STM44/1996 lacked indole production. For the indole production test, consistent results were obtained for both the microplate method and the spot indole test.

Identification of weakly beta-hemolytic porcine spirochetes involves some difficulties because of their less active biochemical nature or due to the frequent presence of atypical phenotypic strains. We examined the usefulness of PCR-RFLP analysis and species-specific PCR combined with a newly devised rapid biochemical test. It was concluded that proper use of PCR-RFLP analysis or speciesspecific PCR is essential for precise identification of
WBHIS. Identification of WBHIS at the species level in routine diagnostic work will definitely contribute in clarifying the pathogenicity of WBHIS.

\section{REFERENCES}

1. Belanger, M. and Jacques, M. 1991. Evaluation of An-Ident system and an indole spot test for the rapid differentiation of porcine treponemes. J. Clin. Microbiol. 29: 1727-2729.

2. Fellström, C. and Gunnarsson, A. 1995. Phenotypical characterization of intestinal spirochaetes isolated from pigs. Res. Vet. Sci. 59: 1-4.

3. Fellström, C., Petterson, B., Thomson, J., Gunnarsson, A., Persson, M. and Johansson, K. E. 1997. Identification of Serpulina species associated with porcine colitis by biochemical analysis and PCR. J. Clin. Microbiol. 35: 462-467.

4. Fellström, C., Karlsson, M., Petterson, B., Zimmerman, U., Gunnarsson, A. and Aspan, A. 1999. Emended description of indole negative and indole positive isolates of Brachyspira (Serpulina) hyodysenteriae. Vet. Microbiol. 70: 225-238.

5. Hampson, D. J. and Duhamel, G. E. 2006. Porcine colonic spirochetosis/intestinal spirochetosis. pp. 755-767. In: Diseases of Swine, 9th ed. (Straw, B. E., Zimmerman, J. J., D'Allaire, D. and Taylor, D. J. eds.), Iowa State University, Ames.

6. Hampson, D. J., Fellström, C. and Thompson, J. R. 2006. Swine dysentery. pp. 785-805. In: Diseases of Swine, 9th ed. (Straw, B. E., Zimmerman, J. J., D'Allaire, D. and Taylor, D. J. eds.), Iowa State University, Ames.

7. Hwang, M. and Ederer, G. M. 1975. Rapid hippurate hydrolysis method for presumptive identification of group B streptococci. J. Clin. Microbiol. 1: 114-115.

8. Kinyon, J. M. and Harris, D. L. 1979. Treponema innocens, a new species of intestinal bacteria, and emended description of the type strain of Treponema hyodysenteriae. Int. J. Syst. Bacteriol. 29: 102-109.

9. Lee,J. I., Hampson, D. J., Lymbery, A. J. and Harders, S. J. 1993. The porcine intestinal spirochaetes: identification of new genetic groups. Vet. Microbiol. 34: 273-285.

10. Neef, N. A., Lysons, R. J., Trott, D. J., Hampson, D. J., Jones, 
P. W. and Morgan, J. H. 1994. Pathogenicity of porcine intestinal spirochetes in gnotobiotic pigs. Infect. Immun. 62: 23952403.

11. Rohde, J., Rothkamp, A. and Gerlach, G. 2002. Differentiation of porcine Brachyspira species by a novel nox PCR-based restriction fragment length polymorphism analysis. J. Clin. Microbiol. 40: 2598-2600.

12. Stanton, T. B., Fournie-Amazouz, E., Postic, D., Trott, D. J., Grimont, P. A. D., Baranton, D., Hampson, D. J. and Saint Girons, I. 1997. Identification of two new species of intestinal spirochetes: Serpulina intermedia sp. nov. and Serpulina murdochii sp. nov. Int. J. Syst .Bacteriol. 47: 1007-1012.

13. Sutter, V. L. and Carter, W. T. 1972. Evaluation of media and reagents for indole-spot tests in anaerobic bacteriology. Am. J. Clin. Pathol. 58: 335-338.

14. Taylor, D. J., Simmons, J. R. and Laird, H. M. 1980. Production of diarrhoea and dysentery in pigs by feeding pure cultures of a spirochaete differing from Treponema hyodysenteriae. Vet. Rec. 106: 326-332.

15. Trott, D., Stanton, T. B., Jensen, N. S., Duhamel, G. E., Johnson, J. L. and Hampson, D. J. 1996. Serpulina pilosicoli sp. nov., the agent of porcine intestinal spirochetosis. Int. J. Syst. Bacteriol. 46: 206-215.

16. Weissenböck, H., Maderner, A., Herzog, A. M., Lussy, H. and Nowotny, N. 2005. Amplification and sequencing of Brachyspira spp. specific portions of nox using paraffin-embedded tissue samples from clinical colitis in Austrian pigs shows frequent solitary presence of Brachyspira murdochii. Vet. Microbiol. 111: 67-75.

17. Wilcock, B. P. and Olander, H. J. 1979. Characterization of the lesions in colons and colonic segments inoculated with pure cultures or colonic content containing Treponema hyodysenteriae. Vet. Pathol. 16: 450-465. 